Supporting Information

\title{
Birch Reduction of Asphaltenes. Synthesis of
}

\section{Hydroasphaltenes}

Manjusha Verma, ${ }^{a}$ Bruce Brinson, ${ }^{a}$ Elena Vishnyakova, ${ }^{a}$ Lawrence B. Alemany, ${ }^{a, b}$

W. E. Billups, ${ }^{a,}{ }^{*}$ Michael Shammaic.

a Department of Chemistry, Rice University, 6100 Main Street, Houston, Texas 77005, USA;

b Shared Equipment Authority, Rice University, 6100 Main Street, Houston, Texas 77005, USA;

${ }^{\mathrm{c}}$ Heavy Oil Research, Baker Hughes, 2929 Allen Parkway, Suite 2100, Houston, Texas 77019, USA.

SI 1. Viscosity of the crude oils

The viscosities of the Ecuadorian crude oils from which the two asphaltenes were isolated and the change in height measured after the Birch reductions are presented in Table S1. Viscosities were measured at $30{ }^{\circ} \mathrm{C}$ using an Anton Parr SVM 3000. 
Table S1. Exfoliated Ecuadorian Asphaltene Properties

\begin{tabular}{lll}
\hline Sample & $\begin{array}{l}\text { Viscosity of crude oil } \\
\left(\mathrm{cP} @ 30^{\circ} \mathrm{C}\right)\end{array}$ & $\begin{array}{l}\text { Height change } \\
\text { determined } \\
\text { AFM }\end{array}$ \\
\hline Asphaltene 1 & 7030 & $1.3 \mathrm{~nm}$ to $0.7 \mathrm{~nm}$ \\
Asphaltene 2 & 45000 & $4 \mathrm{~nm}$ to $2 \mathrm{~nm}$
\end{tabular}

\section{SI 2. Raman spectra of asphaltenes}

Raman spectra were collected for each sample at three locations to determine sample homogeneity. No deterioration takes place on excitation by laser light as no color change was observed during the analysis. For each sample, the Raman spectra could be overlaid. Aromatic core size was calculated based on the Tuinstra and Koenig equation. ${ }^{1-2}$ In light of the very small change in the aromaticity, there was no change in the aromatic core size after the Birch reduction (Table S2). The Raman spectra of the asphaltene can be well compared to a carbonaceous material. The $\mathrm{G}$ band at a frequency around $1580 \mathrm{~cm}^{-1}$ corresponds to the stretching vibration of the sp2 carbon atoms within the aromatic hexagonal sheet as well as those sp2 atoms in the chain and the D1 band around $1350 \mathrm{~cm}^{-1}$ represents the boundary of an ordered-like structure, in this case, the asphaltene molecule. 
SI 2. A. Raman spectra of asphaltene 1

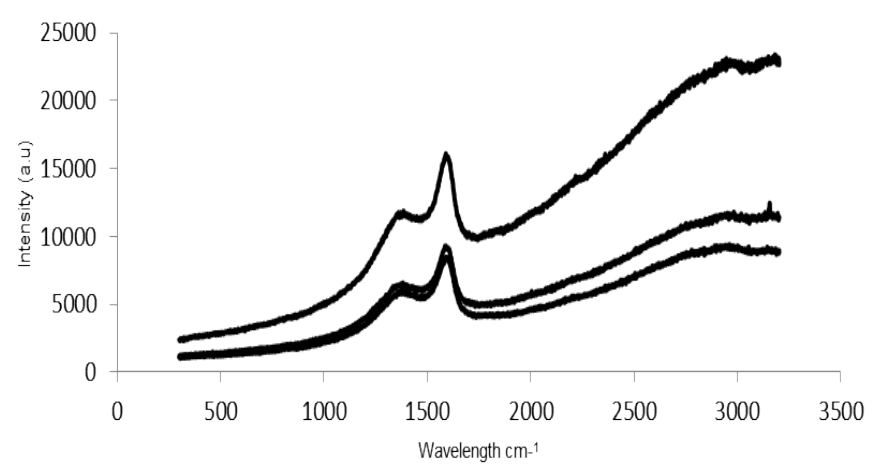

Figure S1. Raman spectra of asphaltene 1. Measurements were carried out in triplicate, demonstrating homogeneity of the system.

SI 2. B. Raman spectra of Birch-reduced asphaltene 1

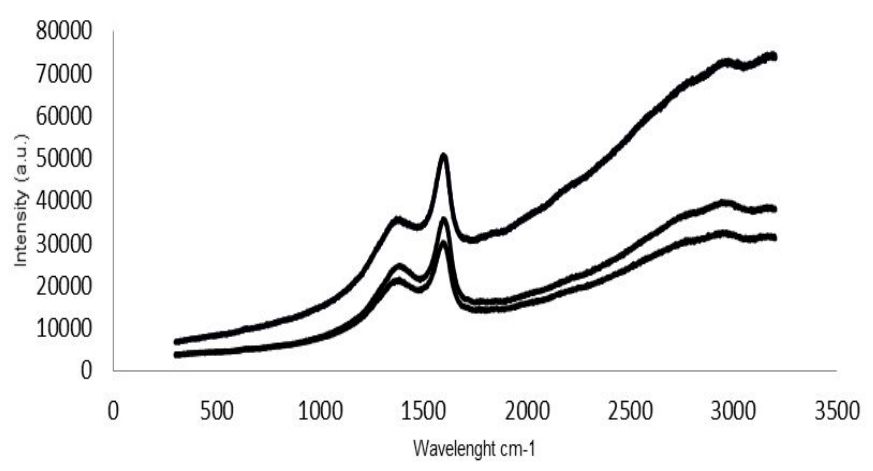

Figure S2. Raman spectra of Birch-reduced asphaltene 1. Measurements were carried out in triplicate, demonstrating homogeneity of the system. 
SI 2. C. Raman spectra of asphaltene 2

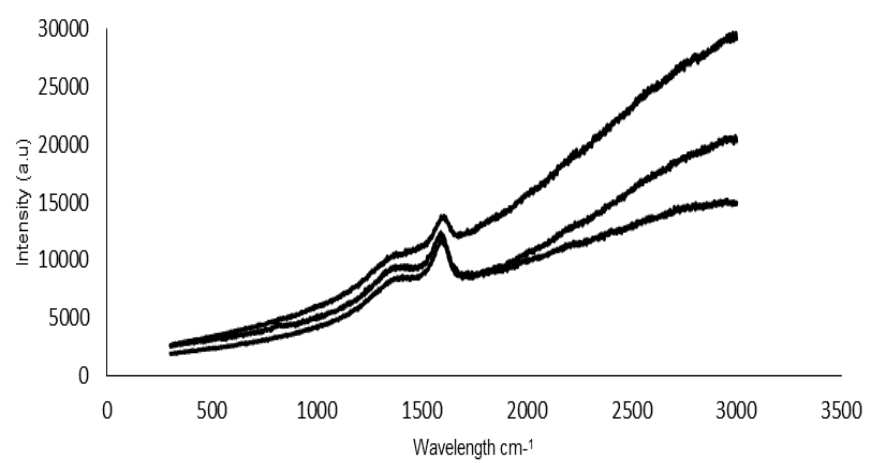

Figure S3. Raman spectra of asphaltene 2. Measurements were carried out in triplicate, demonstrating homogeneity of the system.

SI 2. D. Raman spectra of Birch-reduced asphaltene 2

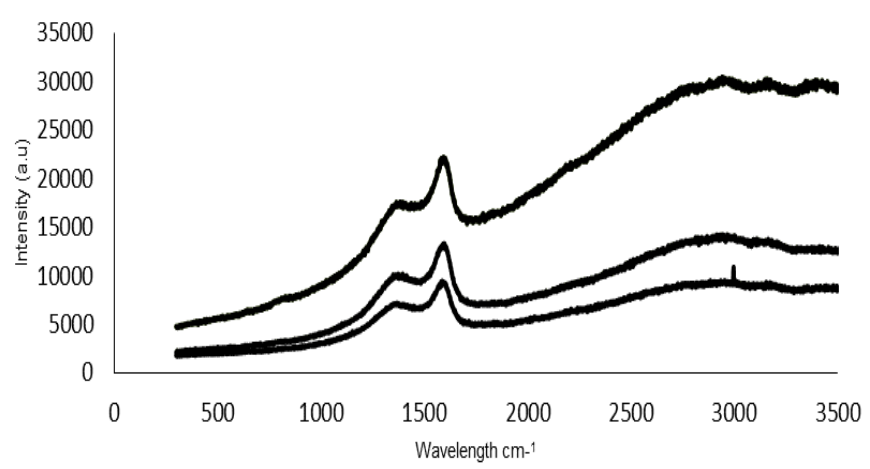

Figure S4. Raman spectra of Birch-reduced asphaltene 2. Measurements were carried out in triplicate, demonstrating homogeneity of the system. 
Table S2. Raman Spectra of asphaltenes and the Birch-reduced products

\begin{tabular}{llll}
\hline Sample & $\begin{array}{l}\text { Average number } \\
\text { of } \\
\text { rings }\end{array}$ & D1 band $\left(\mathrm{cm}^{-1}\right)^{\dagger}$ & G band $\left(\mathrm{cm}^{-1}\right)^{\ddagger}$ \\
\hline Asphaltene 1 & $6-7$ & $1367,1363,1370$ & $1589,1589,1593$ \\
$\begin{array}{l}\text { 0Birch-reduced } \\
\text { asphaltene 1 }\end{array}$ & 7 & $1383,1369,1370$ & $1590,1590,1590$ \\
Asphaltene 2 & $6-7$ & $1376,1372,1383$ & $1584,1588,1587$ \\
$\begin{array}{l}\text { Birch-reduced } \\
\text { asphaltene 2 }\end{array}$ & $5-6$ & $1368,1374,1366$ & $1593,1588,1578$ \\
\hline
\end{tabular}

\footnotetext{
* Calculated by Raman Spectroscopy G band value for three different locations in the same sample

$\dagger \mathrm{D} 1$ band value for three different locations in the same sample

$\$ \mathrm{G}$ band value for three different locations in the same sample
}

SI 3. X-Ray photoelectron spectroscopy of asphaltenes

The asphaltene samples were finely ground and mounted onto a metallic sample holder. An energy correction was made to account for sample charging on the basis of $\mathrm{C}$ (1s) peak at $284.5 \mathrm{eV}$. A discussion on the XPS data on asphaltene 1 and tabulated data for asphaltene 2 and its Birch-reduced product is presented here.

SI 3. A. X-Ray photoelectron spectroscopy of asphaltene 1

The XPS survey spectrum of the asphaltene 1 is shown in Figure S5. The spectrum shows the main elements $\mathrm{C}, \mathrm{N}, \mathrm{O}, \mathrm{S}$ to be present in our asphaltene and type of heterocyclic system present. ( $\mathrm{H}$ cannot be detected by XPS.) We did not observe the presence of lithium remaining in the samples. 


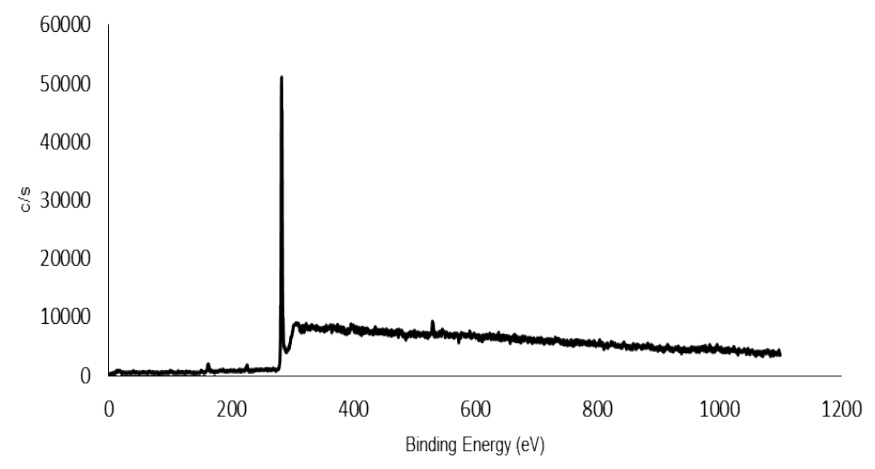

Figure S5. The survey spectrum of asphaltene 1 by XPS

C1s: The asphaltene shows a relatively narrow peak at $284.5 \mathrm{eV}$ that can be assigned to sp2-sp3 hybridized carbon. (Figure S5). The deconvolution of the C1s peak of asphaltene 1 gave two types of peaks at energy position $284.8 \mathrm{eV}$ characteristic of $\mathrm{C}-\mathrm{C}$ and $\mathrm{C}-\mathrm{H}$ bonds with an area of $86.9 \%$ and another peak at $286.0 \mathrm{eV}$ for C-S/C-O for nearly $13.0 \%$ (Figure S6a). 

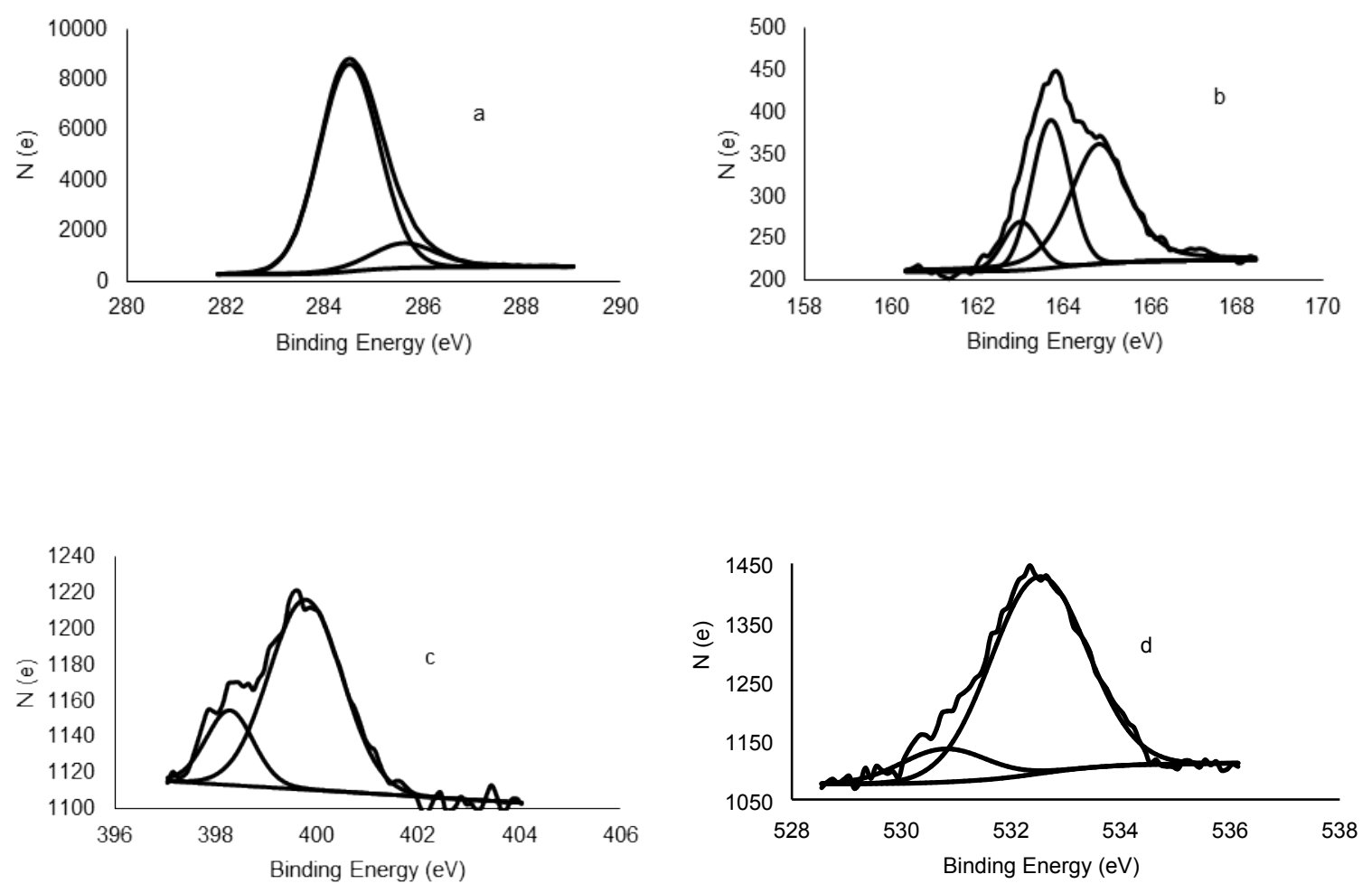

Figure S6. Deconvolution of the XPS spectra of asphaltene 1: (a) C1s, (b) S2p, (c) N1s, (d) O2p.

S2p: The XPS sulfur $2 p$ spectrum from a single species is made up of $2 p 3 / 2$ and $2 p 1 / 2$ components having 2:1 relative intensity and separated by $1.2 \mathrm{eV}$. The $2 \mathrm{p} 3 / 2$ and $2 \mathrm{p} 1 / 2$ peaks were linked by this relationship during the curve resolution process. The energy position of the $2 p 3 / 2$ component sets the energy position of overall sulfur $2 p$ peak. Each XPS sulfur $2 p$ spectrum of an asphaltene sample could be curve-resolved using $2 \mathrm{p} 3 / 2$ peak positions at 162.9 , $163.7,165.9 \mathrm{eV}$. These peaks corresponds to non-aromatic (2.23\%), thiophenic $(62.32 \%)$ and sulfones (35.44 \%) forms, respectively.

N1s: The nitrogen (1s) spectrum from asphaltenes was curve resolved using two peaks at energy position characteristic of pyridine $(398.7 \mathrm{eV}, 20.9 \%)$ and pyrollic $(400.2 \mathrm{eV}, 79.1 \%)$ nitrogen. 
O1s: The O1s from asphaltene 1 shows an intense peak at $532.5 \mathrm{eV}(86.9 \%)$ and a smaller signal at $530.8 \mathrm{eV}(13.1 \%)$ (Figure S6d). The peak at $532.5 \mathrm{eV}$ corresponds to oxygen atoms in the type of $-\mathrm{C}=\mathrm{O}$, such as carbonyl and lactone, and the peak at $530.8 \mathrm{eV}$ is attributed to hydroxyl and etheric oxygens. So the major forms of oxygen present are carbonyl.

SI 3. B. X-Ray photoelectron spectroscopy of asphaltene 2
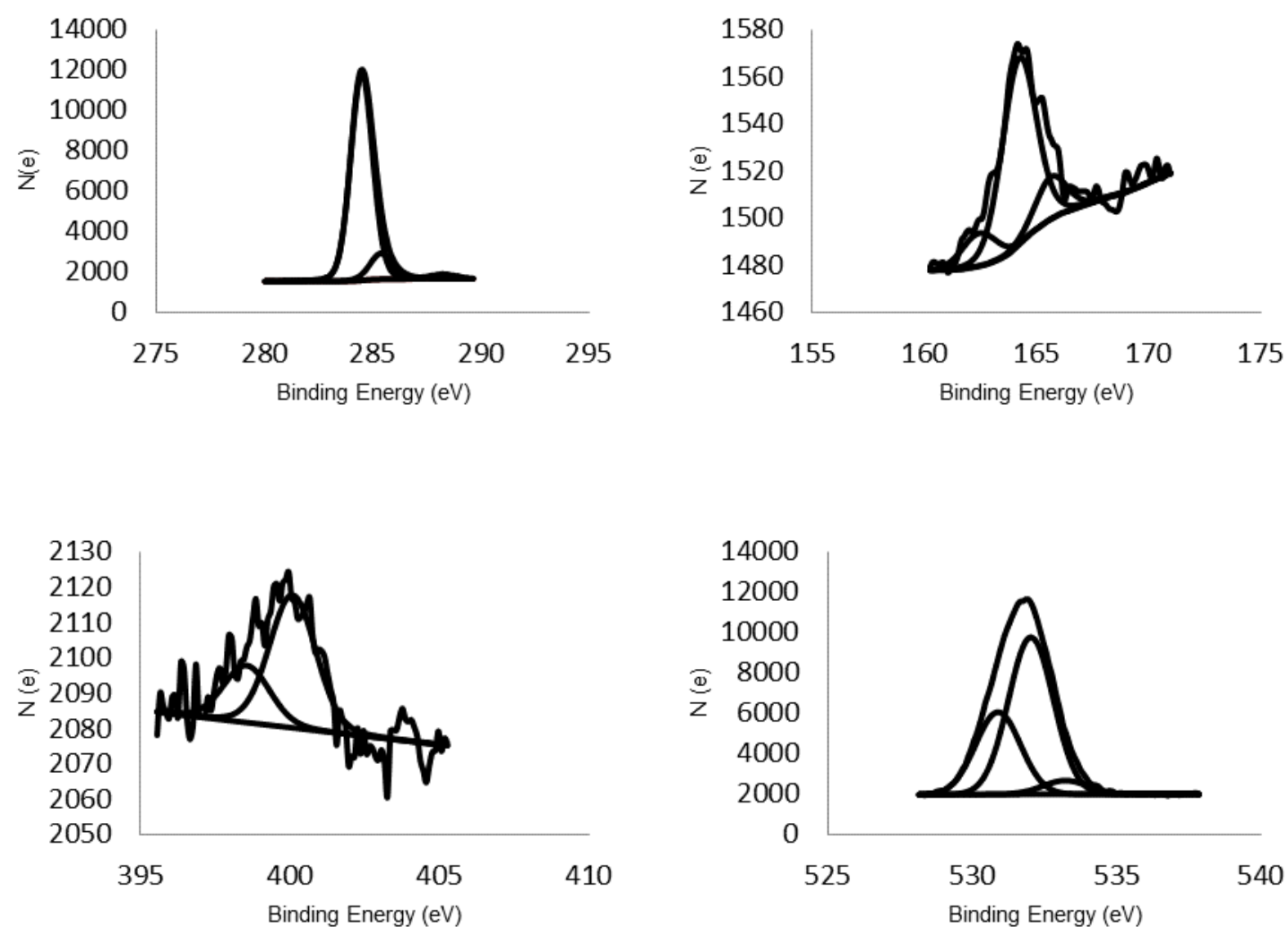

Figure S7. Deconvoluted XPS spectra of asphaltene 2 (a) carbon (b) sulphur (c) nitrogen (d) oxygen. 
Table S3. Percentage, binding energy and structural information for atoms present in asphaltene 2 by XPS

\begin{tabular}{lllll}
\hline Element & Binding energy $(\mathrm{eV})$ & Percentage & Separation $(\mathrm{eV})^{*}$ & $\begin{array}{l}\text { Structural } \\
\text { information }\end{array}$ \\
\hline $\mathrm{C}$ & 284.5 & 86.96 & 0 & C-C, C-H \\
& 285.39 & 11.4 & 0.89 & C-S, C-O, C-N \\
& 288.3 & 1.64 & 3.79 & COOH \\
$\mathrm{S}$ & 162.45 & 12.16 & 0 & Aliphatic sulfur \\
& 164.23 & 72.3 & 1.78 & Thiophenic \\
& 165.65 & 15.54 & 3.2 & Sulfoxide \\
$\mathrm{N}$ & 398.56 & 30.05 & 0 & Pyridine \\
& 400.09 & 69.95 & 1.54 & Pyrrolic \\
& 530.9 & 32.49 & 0 & C-O, O-H \\
& 532.23 & 61.93 & 1.14 & C=O, S-O \\
& 533.23 & 5.58 & 2.33 & Carboxylic oxygen \\
\hline
\end{tabular}

\footnotetext{
${ }^{*}$ Separation between the deconvoluted lowest binding energy band and other bands for each set of elements
} 
SI 3. C. X-ray photoelectron spectroscopy of Birch-reduced asphaltene 2
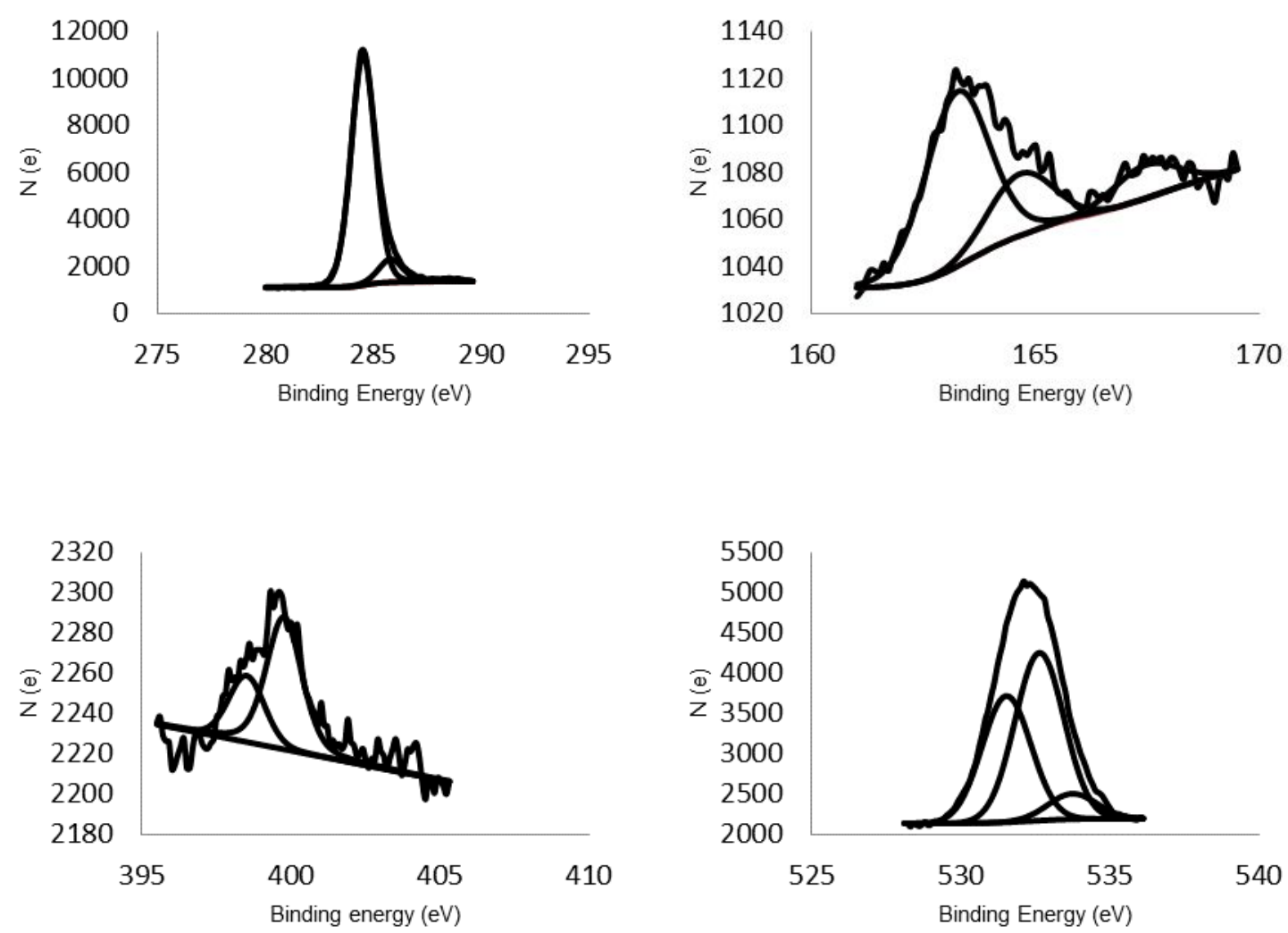

Figure S8. Deconvoluted XPS spectra of Birch-reduced asphaltene 2 (a) carbon (b) sulphur (c) nitrogen (d) oxygen. 
Table S4. Percentage, binding energy and structural information for Birch-reduced asphaltene 2 by XPS

\begin{tabular}{lllll}
\hline Element & Binding energy $(\mathrm{eV})$ & Percentage & Separation $(\mathrm{eV})^{*}$ & $\begin{array}{l}\text { Structural } \\
\text { information }\end{array}$ \\
\hline $\mathrm{C}$ & 284.53 & 89.21 & 0 & $\mathrm{C}-\mathrm{C}, \mathrm{C}-\mathrm{H}$ \\
& 285.81 & 9.84 & 1.27 & $\begin{array}{l}\mathrm{C}=\mathrm{O}, \mathrm{C}-\mathrm{O}, \mathrm{C}-\mathrm{S}, \\
\mathrm{C}-\mathrm{N}\end{array}$ \\
& 288.35 & & & $\mathrm{COOH}$ \\
$\mathrm{S}$ & 163.25 & 0.95 & 3.82 & Aliphatic sulfur \\
& 164.67 & 65.7 & 0 & Thiophene \\
& 167.46 & 22.23 & 1.42 & Sulfones \\
$\mathrm{N}$ & 398.52 & 12.07 & 4.21 & Pyridine \\
& 399.77 & 31.52 & 0 & Pyrrolic \\
& 531.53 & 68.48 & 1.25 & C-O, O-H \\
$\mathrm{O}$ & 532.64 & 39.55 & 0 & C=O, S-O \\
& 533.75 & 52.48 & 1.11 & $\begin{array}{l}\text { Carboxylic } \\
\text { oxygen }\end{array}$ \\
\hline
\end{tabular}

${ }^{*}$ Separation between the deconvoluted lowest binding energy band and other bands for each set of elements REFERENCES

1. Abdallah, W. A.; Yang, Y., Raman spectrum of asphaltene. Energy \& Fuels 2012, 26 (11), 6888-6896.

2. Tuinstra, F.; Koenig, J. L., Raman Spectrum of Graphite. The Journal of Chemical Physics 1970, 53 (3), 1126-1130. 